\title{
RETROSPECTIVE DESCRIPTIVE STUDY OF ABDOMINAL WALL HERNIAS AND THEIR MANAGEMENT
}

\author{
Chandu Sambasivudu ${ }^{1}$, Chandu Vineela ${ }^{2}$, K. P. K. N. Venkata Ramana ${ }^{3}$
}

${ }^{1}$ Consultant Surgeon, Department of General Surgery, NRI Medical College, Guntur, Andhra Pradesh, India.

${ }^{2}$ Consultant Physician, Department of General Medicine, Sri Venkateswara Nursing Home, Tenali, Andhra Pradesh, India.

${ }^{3}$ Consultant Paediatrician, Department of Paediatrics, Sri Venkateswara Nursing Home, Tenali, Andhra Pradesh, India.

\section{ABSTRACT}

\section{BACKGROUND}

This is a retrospective descriptive study of 422 cases of abdominal wall hernias done by single surgeon and their follow-up upto 12 years. Abdominal wall hernias are a group of conditions, which occur mainly through the natural openings and weak areas of abdominal wall- 1. Groin, 2. Ventral part of the anterior abdominal wall, 3. Previous operative sites and 4. Through natural openings and weak areas of abdominal wall.

\section{MATERIALS AND METHODS}

422 cases of abdominal wall hernias treated in the last 12 years along with their management were studied. They were followed upto 12 yrs. The differences in the selection of cases and surgical skill are excluded in the study by including cases done by single surgeon (1st Author) only. Only open surgeries are included in the study to avoid learning curve mistakes.

Mode of Presentation- Elective and emergency surgery and their management is discussed. Anatomical tissue repair, monofilament polypropylene mesh repair in primary and recurrent hernias of various varieties and their results were studied. Bowel resections, omental excisions and separation of bowel adhesions (Adhesiolysis) in sliding and irreducible hernias are analysed. Various complications including mortality are discussed.

\section{RESULTS}

No recurrences were observed in mesh hernioplasty patients. 6 cases of recurrences were observed in anatomical repair patients1.4\%. Monofilament polypropylene mesh was used and fixed to the tissues with 2.0 prolene. 3 patients expired in our series in complicated and strangulated cases- $0.7 \%$.

\section{CONCLUSION}

Prolene mesh repair is definitely superior to anatomical tissue repairs in all cases of abdominal wall hernias. Anatomical tissue repair in young good musculature and small defects gives equally good results in experienced hands.

\section{KEY WORDS}

Abdominal Wall Hernia, Inguinal, Umbilical, Incisional, Strangulation, Bowel Resection, Omentum, Mesh Repair.

HOW TO CITE THIS ARTICLE: Sambasivudu C, Vineela C, Ramana KPKNV. Retrospective descriptive study of abdominal wall hernias and their management. J. Evolution Med. Dent. Sci. 2018;7(31):3544-3548, DOI: 10.14260/jemds/2018/796

\section{BACKGROUND}

Hernia means "rupture" in Latin. It is defined as "Protrusion of a part or whole of the viscus through abnormal opening or a weak area of its containing cavity.[1]" If it occurs in the groin- groin hernia; occurs in the anterior abdominal wallventral hernia; occurring from previous surgical incision siteincisional hernia.

Hernia is known to mankind since long time (1500 BC).[2] Hernia is a non-lethal condition and can wait for many years until either obstr

ucted or strangulated - when it becomes dangerous to life. Groin hernia is classified into inguinal and femoral basing on anatomy - in $14^{\text {th }}$ Century.

Anatomical differences between indirect and direct hernias were reported in $1559 \mathrm{AD}$. It can be either congenital in neonates or in childhood (simple or life-threatening) or acquired in older age.

'Financial or Other Competing Interest': None.

Submission 22-06-2018, Peer Review 17-07-2018,

Acceptance 23-07-2018, Published 30-07-2018.

Corresponding Author:

Dr. Chandu Sambasivudu,

Consultant Surgeon,

22-7-20/1, SVN-Home, Tenali-522201,

Sri Venkateswara Nursing Home, Kothapeta,

Tenali, Guntur District, Andhra Pradesh, India.

E-mail:dr.ch.sinudi@gmail.com

DOI: $10.14260 /$ jemds/2018/796

\section{(c) $($ ) $\$$}

No disease of the human body belonging to the province of the surgeon requires in its treatment a better combination of accurate anatomical knowledge and surgical skill than hernia in all its varieties- Sir Astley Paston Cooper (1804).[1]

Management of hernia demands absolute anatomical details of that area and surgical skill to get best results. Surgical management of groin hernia was first performed in $1^{\text {st }}$ century AD. Surgical principles of groin hernia management are evolved in $700 \mathrm{AD}$.

Standard anatomical repair of inguinal hernia is from Bassini in 1884 AD. [3] He followed 250 patients of hernia repair patients for 5 years and presented in 1889 with $2 \%$ recurrence rate. Recently with increasing life-span, obesity and lifestyle changes, more number of complicated surgeries performed to a person are leading to more number of ventral hernias in addition to naturally occurring groin hernias.[4] Hernioplasty is necessary for those hernia conditions either by open or by laparoscopic surgery. Detailed management of various types of hernias in our study of 422 cases are analysed and their results are given. The differences in the selection of cases and surgical skill are excluded in this study by including the cases done by single surgeon (1 1 st Author) only. Open surgeries are only included in this study to avoid learning curve mistakes. 


\section{Aim of Study}

To know the efficacy of anatomical tissue repair and mesh hernioplasty in abdominal wall hernias.

\section{MATERIALS AND METHODS}

It is a retrospective descriptive study. 422 cases of abdominal wall hernias \& their management were studied in the last 12 years. They are followed upto 12 years. The differences in the selection of cases and surgical skill are excluded in the study by including the cases done by single surgeon (1 $1^{\text {st }}$ Author) only. Open surgeries are only included in this study to avoid learning curve mistakes.

No recurrences were observed in mesh hernioplasty patients. Six cases of recurrences observed in anatomical repair patients- $(1.4 \%)$. Monofilament polypropylene mesh was used and fixed to the tissues with 2-0 prolene. Three patients expired in our series in complicated and strangulated cases- $0.7 \%$.

Prolene mesh repair is definitely superior to anatomical tissue repairs in all cases of abdominal wall hernias. Anatomical tissue repair in young good musculature and small defects give equally good results in experienced hands.

\begin{tabular}{|c|c|c|c|}
\hline Sl. No. & Age in Years & No. of Cases & Percentage \\
\hline 1 & $0-5$ & 18 & $4.2 \%$ \\
\hline 2 & $6-10$ & 6 & $1.4 \%$ \\
\hline 3 & $11-20$ & 20 & $4.7 \%$ \\
\hline 4 & $21-40$ & 114 & $27 \%$ \\
\hline 5 & $41-60$ & 170 & $40.28 \%$ \\
\hline 6 & $61-80$ & 76 & $18 \%$ \\
\hline 7 & $>80$ & 18 & $4.2 \%$ \\
\hline \multicolumn{4}{|c|}{ Table 1. Age and Side Wise Distribution } \\
\hline 8 & Total & $\mathbf{4 2 2}$ & $\mathbf{1 0 0 \%}$ \\
\hline 9 & SIDE & 176 & $58.7 \%$ \\
\hline 10 & Right & 108 & $36.0 \%$ \\
\hline \multicolumn{4}{|c|}{ Left } \\
\hline
\end{tabular}

\begin{tabular}{|c|c|c|c|}
\hline Sl. No. & Type & Total No. & $\mathbf{\%}$ \\
\hline $\begin{array}{c}\text { 1. } \\
\text { Uncomplicated }\end{array}$ & Reducible & 322 & 76.3 \\
\hline 2. Complicated & $\begin{array}{c}\text { Irreducible, Obstructed } \\
\text { and Strangulated }\end{array}$ & 100 & 23.7 \\
\hline & $\begin{array}{c}\text { A. Sliding Hernia and } \\
\text { (Left Colon Reduction) }\end{array}$ & 12 & 2.8 \\
\hline & B. Adhesiolysis & 25 & 5.9 \\
\hline & C. Hysterectomy & 1 & 0.24 \\
\hline & D. Omental excision & 48 & 11.4 \\
\hline & E. Bowel resections & 14 & 3.3 \\
\hline & F. Strangulated & 18 & 4.2 \\
\hline & Table 2. Management Profile \\
\hline \multicolumn{3}{|c}{} \\
\hline
\end{tabular}

\begin{tabular}{|c|c|c|}
\hline Mode & No. of Cases & Percentage \\
\hline Elective & 346 & 82 \\
\hline Emergency & 76 & 18 \\
\hline \multicolumn{2}{|c|}{ Table 3. Mode of Presentation to Hospital } \\
\hline
\end{tabular}

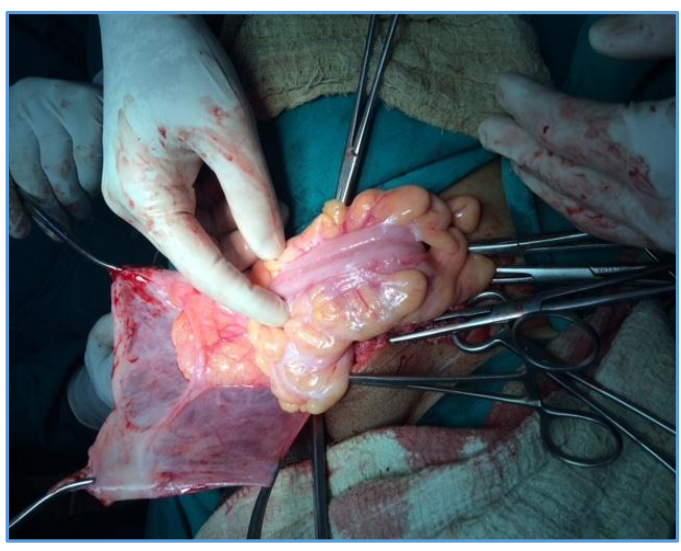

Figure 1. Left Colon in Indirect Inguinal Hernia

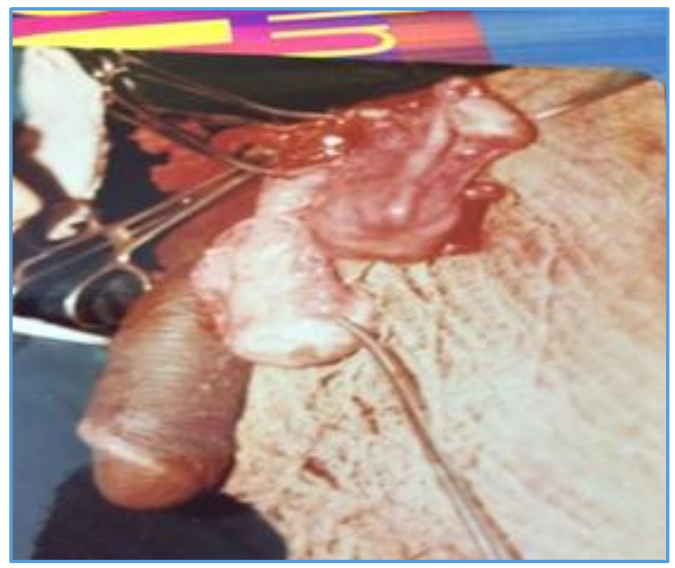

Figure 2. Left Indirect Inguinal Hernia contains Uterus, Tubes and Ovaries in Male

\section{RESULTS}

Age

Hernia is more common in $5^{\text {th }}$ and $6^{\text {th }}$ decades $-40 \%$ followed by $3^{\text {rd }}$ and $4^{\text {th }}$ decades $-27 \%$ (Table 1 ).

\section{Side Wise}

We have found right-sided inguinal hernias in 58.7\% compared to left-sided $36 \%$ as seen in Table 1 .

\section{Inguinal- 71\%}

Inguinal hernias were observed in our series (300/422)- 71\% of all abdominal wall hernias. Out of the inguinal hernias, males are 98\% (294/300) and females are 2\% (6/300). Femoral hernias- $1.4 \%$ was seen only in females $(6 / 422)-$ $1.4 \%$ in our study as seen in Table 2.

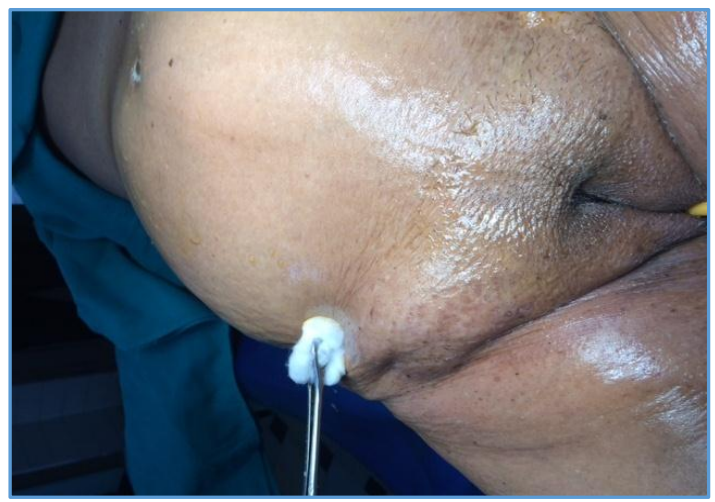

Figure 3. Strangulated Femoral Hernia 
Next Common Variety Incisional Hernia- 12.8\%

Incisional hernias are more common in females 44/54 81.5\%. Almost all of them are in lower midline incisions for hysterectomies and other pelvic surgeries. Males - (10/54) $18.5 \%$ - (Table 2). They are upper midline, subcostal and appendicular incision hernias.

\section{Umbilical - 8.5\%}

Umbilical hernias are more common after middle age, which constitute $8.5 \%$ of all hernias. They are mainly due to obesity in adult life. It is seen in $66.6 \%$ in males $(24 / 36)$ - in contrast to the standard teaching of higher incidence in females $(12 / 36)-33.3 \%$.

\section{Epigastric Hernia - $\mathbf{6 . 2 \%}$}

$6.2 \%$ of all hernias are epigastric hernias in my series. Majority of them are male persons, 92\%. Only (2/26) - 8\% are females $-72 \%$ of hernia patients presented to the hospital as elective and $18 \%$ as emergency as seen in Table 3 .

\section{Criteria to Select for Mesh Repair - in our Cases are}

1. Large sized inguinal hernias, mostly direct variety.

2. Obese people and smokers.

3. Aged.

4. Recurrent hernias.

5. Non-infected cases.

6. Incisional hernias.

7. Affordability and acceptance of the patient.

\section{Criteria for Anatomical Repair}

1. Young.

2. Good musculature and fascia.

3. Small defect in the fascia/ Linea alba.

4. Not willing to get mesh insertion.

5. Infected cases (Strangulated - Bowel Gangrenous).

6. Non-affordability.

\section{Management}

All people are operated by single surgeon (1 $1^{\text {st }}$ Author). Both elective and emergencies are operated under Spinal/ General anaesthesia. Uncomplicated hernias (Reducible hernias) are (322/422) - 76.3\%. Simple herniotomy plus anatomical tissue herniorrhaphy and Lichtenstein mesh hernioplasty[5] was done basing on the criteria followed by us. I always fix mesh with 2-0 prolene suture. Large sized, obese, smokers, aged, recurrent, non-infected and incisional hernias are operated with Lichtenstein mesh hernioplasty.

\section{Complicated - $\mathbf{2 3 . 7 \%}$}

Simple irreducible/ obstructed/ strangulated hernias constitute $(100 / 422)-23.7 \%$ of all hernias. Out of them - on exploration and release of minor adhesions 25 cases $-5.9 \%$ reduced (Fig. 1) without any problem. Whereas in 48 cases omentum is matted, sometimes haemorrhagic - which needed excisions $-11.4 \%$. In large irreducible hernias in left inguinal region - sigmoid colon present in 12 cases - 2.8\%. In strangulated hernias of incisional, inguinal, femoral and umbilical hernias - after careful release of all adhesions - the gangrenous small bowel and omentum were resected and end-to-end anastomosis was done in 14 cases - $3.3 \%$ as seen in Table 2. In 35 years, male left indirect inguinal hernia in uterus and fallopian tubes are present - which were excised as shown in Figure 2.

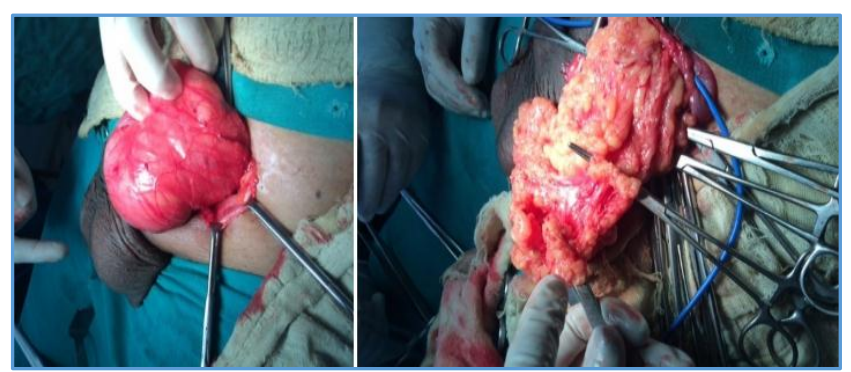

Figure 4 ( $A$ and B). Matted Omentum in Indirect Inguinal Hernia. Excision of the Omentum

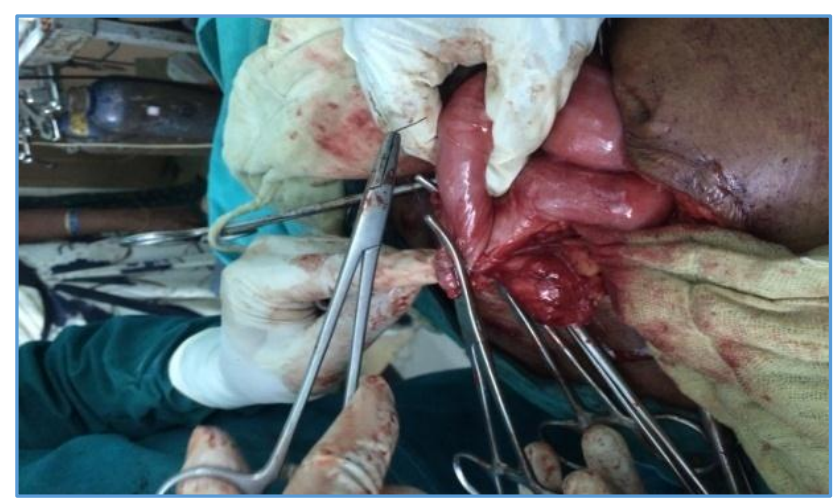

Figure 5. Releasing of Densely Adherent Bowel

\section{Complications}

1. We have operated maximum number of patients under spinal anaesthesia. General anaesthesia is given whenever necessary. Minor wound infections occurred in 14 cases, which resolved with antibiotics and dressings in 5 to 8 days (14/422) - 3.3\%.

2. Stitch abscess occurred in 10 patients, where subcutaneous catgut is not absorbed which resolved after opening it $(10 / 422)-2.3 \%$.

3. Seromas collected in the spermatic cord and scrotum in 6 cases, which resolved after 10 to 15 days of treatment with NSAID (6/422) - 1.4\%.

4. Tunica vaginalis hydrocele occurred in 2 patients after 2 months (2/422) - 0.47\%.

5. In a case of inguinal mesh repair - a piece of mesh projecting out of the wound due to infection. After excising the projecting pieces of the mesh around $0.5 \mathrm{~cm}$ each - the wound healed. There are no haematomas in our series.

\section{Mortality}

3 Patients expired in our series. A 60 years old patient with strangulated inguinal hernia which needed bowel resection later developed anastomotic leak - expired. 2nd Patient 87 years old female with strangulated femoral hernia expired on $9^{\text {th }}$ day due to respiratory complications. $120 \mathrm{kgs}$ obese male with recurrent incisional hernia - strangulated - needed massive bowel resection of 10 feet (Fig. 6 (A and B)), developed anastomotic leak - developed faecal fistula - died after 3 months (3/422) - 0.7\%.[6,7,8] 

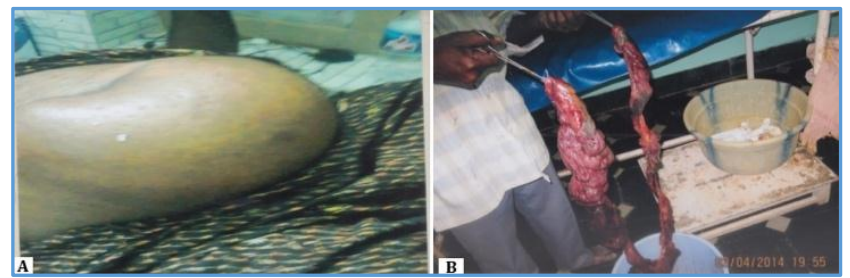

Figure $6(A, B)$. Recurrent Strangulated Incisional Hernia Massive Bowel Excision in the same case Obese

\section{Recurrences}

No recurrence was observed in mesh hernioplasty patients. Anatomical repair patients - 2 recurrences in less than 1 year - in inguinal hernia. They are obese and not willing for mesh repairs 10 years back. Umbilical - 2, epigastric hernia - 2 each $6 / 422-1.4 \%$. We have enquired about the operated patients for the last 12 years and we did not get any recurrence information more than those patients. ${ }^{[9]}$

\section{DISCUSSION}

Hernia is one of the commonest general surgical problems operated by junior and senior surgeons. It is quite simple to manage in early cases; hence we give chances in postgraduate training itself. Sometimes, it is highly complicated when it is sliding variety/ obstructed with adhesions/ large irreducible obstructed incisional hernias, and in strangulated cases where it needs bowel resection/ adherent and matted omentum - which needs excision.

There are many types of hernia repairs done by many surgeons all over the world since centuries. No procedure is absolutely free of recurrences or complications. Hence, diversity of procedures to treat are in practice. In my opinion, each case should be treated for the suited repair.

\section{Age}

Hernias are most common in middle part of life. $67 \%$ was observed in between 3-6 decades in our series. These are acquired variety with increased intra-abdominal pressure due to any cause- Obesity, COPD and defective collagen patients. It is comparable to the studies of earlier reports by Dr. Vivek Laxmanbhai Patel, Dr. Pooja Akash Pachani, et al[10] and also Dr. S. Vijay Kumar[11,12] et al in 2016.

In our series $-4.2 \%$ incidence is seen in the age group of 1 - 5 years - mostly due to congenital hernias. Overall, the incidence of inguinal hernia in children is 0.8 to $4.4 \%$ as reported by Mary l Brand et al.[13] The incidence decreased between $6-20$ years $-1.4 \%$. In $7^{\text {th }}$ and $8^{\text {th }}$ decades - it is fairly common - $18 \%$. After 80 , it is less due to decreased survival. Complications and mortality is high in $8^{\text {th }}$ and $9^{\text {th }}$ decades and in emergency surgeries in our series, which is comparable to the other studies like Compagna et al 2013[7] and Helgstrand et al.[8]

\section{Side}

Right-sided inguinal hernias are more common due to late descent of testis into the scrotum in foetal life and also due to failure of obliteration of process vaginalis. It is comparable to the studies of Mary L Brand et al in 2008[13] - surgical clinics of North America, which are quoted $60 \%$ on right side. Tanyel et al suggested that failure of regression of smooth muscle in processus vaginalis may have a role in the development of indirect inguinal hernia.[14,15] We had $5.3 \%$ bilateral hernias at presentation, unlike $23.8 \%$ in the study of Dr. S. Vijay Kumar[11] et al 2016.

\section{Region Wise/ Groin}

Inguinal hernias are commonest of all abdominal wall hernias (71\%) in our series. It is comparable to the study of Dr. C. Palanivelu et al in 2008 as $76 \% .^{[16]}$ Indirect hernias $73.3 \%$, Direct hernias 17.3\%, Pantaloon (28/300) - 9.3\% are observed in our series.

In Western series femoral hernias are quoted upto $22.4 \%$ of female groin hernias and $1.8 \%$ of male groin hernias ${ }^{[17]}$ (Annals of surgery, 2007). But in our series femoral hernias are seen only in females, not seen in males. Femoral hernias are less common in our series when compared to western literature $(<2 \%$ versus $10 \%$ to $20 \%)$ in other series.[17] Femoral and inguinal hernias are equal in number in females in contrast to western population. This might be due to changes in pelvic girdle differences between West and India. This is also corroborated by other Indian reports. [11]

\section{Incisional Hernia}

High incidence may be due to more no. of complicated surgeries done to a person due to imperfect closure of the abdominal wall and post-operative infections of the incisions. ${ }^{[8]}$ Incisional hernias are increasing gradually. The same incidence is comparable to the other studies (15 to 20\%).[18]

\section{Epigastric and Umbilical Hernia}

Epigastric and umbilical hernias are less common in females in this semi-rural area - might be due to agricultural working nature of the women - thereby less obesity - less incidence of epigastric and umbilical hernias in females.

\section{Management}

In the past decades, acceptability and affordability of mesh repair is less in this region. Now with improved lifestyle and living standards - people are accepting mesh hernioplasties. We prefer monofilament polypropylene mesh, because it is biologically inert in almost every person (Rajvilas Narkhede IJS)[19] it is having less intertwined areas, thereby decreased bacterial adherence to this mesh when compared to multifilament mesh - which contains more surface area and intertwines. Monofilament meshes have decreased antiadhesive coating to staphylococcus attachment. $[20,21,22,23]$ There are reports of mesh infection rate varying from $5 \%$ to $10 \% .[24,25]$ Necrotising fasciitis like serious life-threatening infections are reported in the literature after mesh insertion. ${ }^{[26]}$ Smoking is associated with connective tissue disruption, thereby increasing the incidence of recurrence. [27]

We have done mesh repair as per the earlier criteria only.

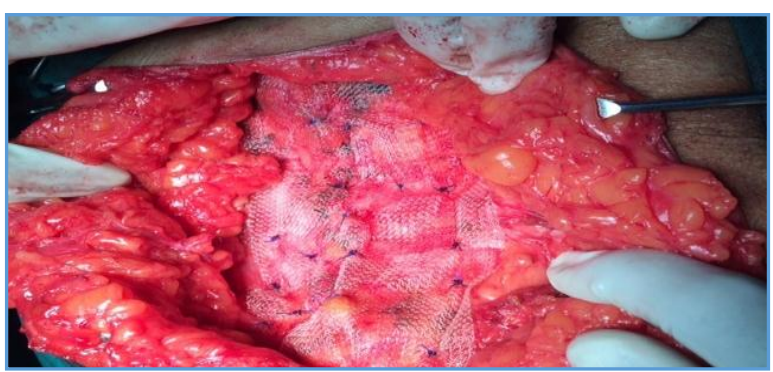

Figure 7. Prolene Mesh Repair in Incisional Hernia 
We have done mesh hernioplasty in $35.07 \%$ of all cases, highest being incisional hernia $62.9 \%$ followed by epigastric $46.2 \%$, umbilical $38.9 \%$ and inguinal $29.3 \%$. In the last 2 years figure is increasing - 36/62 - 58\%. It shows mesh hernioplasty rate is increased.

In spite of high rate of anatomical repair in all varieties of abdominal wall hernias, the recurrence rate is $1.4 \%$. Even though some patients might have not responded to enquiry it is not more than $2 \%$ to $3 \%$ - comparable to the results of Janu PG et al.[28, 10] Hence, in suitable cases anatomical repair should be done. Mesh hernioplasty is definitely superior to other varieties of repair (very negligible recurrences).

This is also comparable to the reports of Dr. Vivek Laxmanbhai Patel et al, which reported $0 \%$ recurrence in Lichtenstein mesh hernioplasty and $2 \%$ in anatomical tissue repair.[10]

\section{CONCLUSION}

Prolene mesh repair is definitely superior to anatomical tissue repairs in all cases of abdominal wall hernias. Specifically, so in obese, recurrent, weak abdominal wall musculature of old age and collagen tissue defect people. Anatomical tissue repair in young patients with good musculature, and small defects give equally good results in experienced hands. In Indian rural population, early small hernias and in young people, anatomical repair is suggested to avoid cost, foreign body placement and mesh infection. Hence, we recommend anatomical tissue repair in suitable cases. Anatomical repair has cured lakhs of patients worldwide for centuries in expert hands of surgeons.

\section{REFERENCES}

[1] Williams N, O'Connell PR. Text book of Bailey and Love's - Short ractice of surgery. 25th edn. CRC Press 2008: p. 968.

[2] Zinner MJ. Maingot's text book of abdominal operations. 12th edn. McGraw-Hill 2013: p. 123 \& 125.

[3] Bassini E. Nouvo Method per la Cura Radicale dell Ernia Inguinale. Padova, Italy: Prosperini 1889.

[4] Dabbas N. Changing incidence of abdominal hernias. Journals.sagepub.com 2010.

[5] Lichtenstein IL, Shulman AG, Amid PK. The cause, prevention and treatment of recurrent groin hernia. Surg Clin North Am 1993;73(3):529-44.

[6] Haapaniemi S, Sandblom G, Nilsson E. Mortality after elective and emergency surgery for inguinal and femoral hernia. Hernia 1999;3(4):205-8.

[7] Compagna R, Rossi R, Fappiano F, et al. Emergency groin hernia repair: implications in elderly. BMC Surgery 2013;13(Suppl 2):S29.

[8] Helgstrand F, Rosenberg J, Kehlet H, et al. Outcomes after emergency versus elective ventral hernia repair: a prospective nationwide study. World Journal of Surgery 2013;37(10):2273-9.

[9] Luijendijk RW, Hop WC, van den Tol MP, et al. A comparison of suture repair with mesh repair for incisional hernia. N Engl J Med 2000;343(6):392-8.

[10] Patel VL, Pachani PA, Pachani AB, et al. Role of Lichtenstein repair (meshplasty) versus modified Bassini's repair (herniorraphy) in management of inguinal hernia. International Journal of Information Research and Review 2016;3(11):3237-44.
[11] Vijayakumar S, Alagarsamy R. A study on incidence and risk factors of inguinal hernia in ESI population. IOSR Journal of Dental and Medical Sciences (IOSR JDMS) 2016;15(7): Ver. VIII p. 32-4.

[12] Sidhu BS. Tension free hernioplasty under local anesthesia. Gilbert's repair. Indian J Cure NY Med J 1999;53:615-7.

[13] Brandt ML. Pediatric hernias. Surgical Clinics of North America 2008;88(1):27-43.

[14] Tanyel FC, Dagdeviren A, Muftuoglu S, et al. Inguinal hernia revisited through comparative evaluation of peritoneum, processus vaginalis and sacs obtained from children with hernia, hydrocele and undescended testis. J Pediatr Surg 1999;34(4):552-5.

[15] Tanyel FC, Okur HD. Autonomic nervous system appears to play a role in obliteration of processus vaginalis. Hernia 2004;8(2):149-54.

[16] Palanivelu C. Result of hand sutured laproscopic hernioplasty: an effective method of repair. Indian Journal of Surgery 2000;62(5):339-41.

[17] Nilsson H, Stylianidis G, Haapamakai M, et al. Mortality after groin hernia surgery. Annals of Surgery 2007;245(4):656-60. (Swedish hernia register)

[18] Doherty GM. Current diagnosis \& treatment - surgery. Vol. 2. 14th edn. McGraw-Hill Education/Medical 2015: p. 768.

[19] Narkhede R, Shah NM, Dalal PR, et al. Postoperative mesh infection. Indian J Surg 2015;77(4):322-6.

[20] Paton BL, Novitsky YW, Zerey M, et al. Management of infections of polytetrafluoroethylene - based mesh. Surg Infect (Larchmt) 2007;8(3):337-41.

[21] Harrell AG, Novitsky YW, Kercher KW, et al. In vitro infectability of prosthetic mesh by methicillin resistant Staphylococcus aureus. Hernia 2006;10(2):120-4.

[22] Halaweish I, Harth K, Broome AM, et al. Novel in vitro model for assessing susceptibility of synthetic hernia repair meshes to staphylococus aureus infection using green fluorescent protein - labeled bacteria and modern imaging techniques. Surg Infect (Larchmt) 2010;11(5):449-54.

[23] Sanchez VM, Abi-Haidar YE, Itani KM, et al. Mesh infection in ventral incisional hernia repair: incidence, contributing factors and treatment. Surg Infect (Larchmt) 2011;12(3):205-10.

[24] Mavros MN, Athanasiou S, Alexiou VG, et al. Risk factors for mesh-related infections after hernia repair surgery: meta-analysis of cohort studies. World J Surg 2011;35(11):2389-98.

[25] Chauhan PV, Desai HK. Comparative study on surgical techniques of incisional hernia repair. National Journal of Medical Research 2016;6(3):230-2.

[26] Turner EJ, Owen ERTC, Reddy K. Necrotising fasciitis following inguinal hernia mesh repair. BMJ Case Rep 2009;2009. pii: bcr01.2009. 1535.

[27] Wagh PV, Leverich AP, Sun CN, et al. Direct inguinal herniation in men: a disease of collagen. J Surg Res 1974;17(6):425-33.

[28] Janu PG, Sellers KD, Mangiante EC. Mesh inguinal herniorrhaphy: a ten-year review. Am Surg 1997;63(12):1065-9: discussion 1069-71. 